Article

\title{
Impact on the Gas Barrier Property of Silicon Oxide Films Prepared by Tetramethylsilane-Based PECVD Incorporating with Ammonia
}

\author{
Hua-Wen Liu ${ }^{1}$, Tai-Hong Chen ${ }^{2}$, Chun-Hao Chang ${ }^{2}$, Shao-Kai Lu ${ }^{1}$, Yi-Cyuan Lin ${ }^{1}$ and \\ Day-Shan Liu ${ }^{1, *}$ \\ 1 Institute of Electro-Optical and Materials Science, National Formosa University, Yunlin 63201, Taiwan; \\ Neroliu0416@gmail.com (H.-W.L.); eric0916a@gmail.com (S.-K.L.); fun318023@hotmail.com (Y.-C.L.) \\ 2 Industrial Technology Research Institute, Liujia, Tainan 734, Taiwan; tsaicc1221@gmail.com (T.-H.C.); \\ a0922639175@gmail.com (C.-H.C.) \\ * Correspondence: dsliu@nfu.edu.tw; Tel.: +886-5-631-5665
}

Academic Editors: Stephen D. Prior and Gianfranco Pacchioni

Received: 27 October 2016; Accepted: 28 December 2016; Published: 5 January 2017

\begin{abstract}
The gas barrier property of a silicon oxide $\left(\mathrm{SiO}_{x}\right)$ film synthesized from plasma-enhanced chemical vapor deposition using the tetramethysilane (TMS)-oxygen gas mixture was modified by introducing ammonia gas in the glow discharge. The change in the glow discharge with the ammonia gas incorporation was monitored by an optical emission spectrometer (OES). Structures, chemical bond configurations, and material properties of the resulting films were investigated. The introduced ammonia gas in the TMS-oxygen plasma resulted in emission lines dominated by the $\mathrm{N}_{2}$ and $\mathrm{CN}$ species with the suppression of the $\mathrm{OH}$ and oxygen-related radicals, thereby introducing nitrogen and carbon atoms in the deposited film. A silicon oxynitride $\left(\mathrm{SiO}_{x} \mathrm{~N}_{y}\right)$ film had the best surface morphology and the lowest residual internal stress was achievable by controlling the reactant gas flow ratio of the ammonia and oxygen. The barrier property to the water vapor permeation of the silicon oxide film ( $1.65 \mathrm{~g} / \mathrm{m}^{2} /$ day) deposited onto the polyethylene terephthalate (PET) substrate was thus greatly improved to $0.06 \mathrm{~g} / \mathrm{m}^{2} /$ day for the film synthesized from an adequate TMS-oxygen-ammonia gas mixture.
\end{abstract}

Keywords: silicon oxide; gas barrier; optical emission spectrometer; silicon oxynitride; TMS-oxygen-ammonia gas mixture

\section{Introduction}

Silicon oxide $\left(\mathrm{SiO}_{x}\right)$ film is comprehensively deposited for passivation, insulation, waveguide, detector and sensor, and anti-reflection applications, as it has many advantages over other materials such as optical transparency with a low refractive index, impact resistance, and environmental and chemical stability [1-4]. This glassy coating which offers the conditions for a barrier layer against moisture, gas, and aromas also has been employed for deposition onto plastic substrates for packaging applications $[5,6]$. However, since most of the plastic substrates are very sensitive to temperature, significant nanometer- to micrometer-sized defects appear in the low-temperature deposited $\mathrm{SiO}_{x}$ film, thereby limiting the barrier property of the $\mathrm{SiO}_{x}$ film when deposited onto the plastic substrates. Accordingly, methods have been developed to strengthen the barrier property of the low-temperature deposited $\mathrm{SiO}_{x}$ film to water vapor and oxygen permeation. One of the methods is to design a multilayered structure consisting of organic/inorganic or inorganic/inorganic coatings to slow down and decouple the diffusion of the water vapor and oxygen into the plastic-based components/devices. For instant, Jeong et al. demonstrated a 3.5 dyads multilayered barrier composed of $\mathrm{SiO}_{x}$ and parylene deposited by plasma-enhanced chemical vapor deposition (PECVD) and a parylene coating, 
respectively, to reach a water vapor transmission rate (WVTR) of $0.3 \mathrm{~g} / \mathrm{m}^{2} /$ day when deposited onto a polyethersulfone (PES) substrate [7]. Wuu et al. addressed a low WVTR of $0.01 \mathrm{~g} / \mathrm{m}^{2} /$ day using the $\mathrm{SiO}_{x} / \mathrm{SiN}_{x}$ multilayered structure with the insertion of a parylene layer when deposited onto a polycarbonate (PC) substrate [8]. However, since the above-mentioned depositions were carried out using two different systems which might induce additional contaminants and prolong the fabrication time, we developed an organosilicon $/ \mathrm{SiO}_{x}$ multilayered structure consecutively prepared in one PECVD system by simply altering the tetramethysilane (TMS) monomer and TMS- $\mathrm{O}_{2}$ gas mixture, respectively. A very low WVTR of $4.4 \times 10^{-4} \mathrm{~g} / \mathrm{m}^{2} /$ day was achieved with the polyethylene terephthalate (PET) substrate coated with a three-paired multilayered structure possessing an optimal residual internal stress [9]. Recently, Alipour et al. also developed two polymer-based multilayered structures instead of the organic/inorganic structure to result in resistance to crack growth under tensile strain and a decrease in the oxygen transmission rate [10]. In addition to preparing the multilayered structure to prolong the diffusion path for the water vapor and oxygen permeation, another promising method to enhance the barrier property of the $\mathrm{SiO}_{x}$ film is to improve the film's density and uniform coverage of topological structures via the incorporation of nitrogen atoms. Lau et al. investigated the optical and material properties of the sputtered $-\mathrm{SiO}_{2},-\mathrm{SiO}_{x} \mathrm{~N}_{y}$, and $-\mathrm{Si}_{3} \mathrm{~N}_{4}$ films. They found that the barrier property of the $\mathrm{SiO}_{2}$ film to water vapor permeation was quantitatively improved with low nitrogen contents in the reactive gas mixture due to the optimization of the mechanical stress and the enhancement of the coating density [11]. Lee et al. discussed the effect of the $\mathrm{N}_{2}$ flow rate in the ion-beam source on the evaporated $-\mathrm{SiO}_{x}$ film. The resulting $\mathrm{SiO}_{x} \mathrm{~N}_{y}$ prepared under the $\mathrm{N}_{2}$ ion source of $40 \mathrm{sccm}$ exhibited a high refractive index $(\sim 1.535)$ and an optimal film density $\left(\sim 2.5 \mathrm{~g} / \mathrm{cm}^{3}\right)$, thereby corresponding to the lowest WVTR of $0.08 \mathrm{~g} / \mathrm{m}^{2} /$ day when deposited onto a polyethylene naphthalate (PEN) substrate [12]. Furthermore, Jin et al. reported that the WVTR of a $\mathrm{SiO}_{x}$ film coated onto a PET substrate was significantly decreased from 0.25 to $0.07 \mathrm{~g} / \mathrm{m}^{2} /$ day as the glow discharge was incorporated with $\mathrm{N}_{2}$ gas [13].

In this work, with the aim to further optimize the barrier property of the $\mathrm{SiO}_{x}$ film synthesized from the TMS- $\mathrm{O}_{2}$ gas mixture, the evolutions in the barrier property of the $\mathrm{SiO}_{x}$ film synthesized from the TMS- $\mathrm{O}_{2}$ gas mixture with the incorporation of the ammonia gas were investigated. The change in the chemical bond configurations and element compositions of the resulting films were linked to the gas flow ratio of the ammonia gas in the glow discharge. The impact on the surface roughness, particle morphology and residual internal stress of the deposited films synthesized from the ammonia gas introduced into the TMS- $\mathrm{O}_{2}$ gas mixture were also elucidated.

\section{Experimental Section}

The 100-nm-thick silicon-containing films were deposited onto the silicon and PET substrates using a planar-type capacitively coupled radio-frequency (13.56 MHz) discharge PECVD system. The PET substrate was cleaned with isopropyl alcohol (IPA) in an ultrasonic washer prior to the film deposition. Vaporized source from liquid tetramethylsilane (TMS, $\left.\mathrm{Si}\left(\mathrm{CH}_{3}\right)_{4}\right)$ was employed as the silicon precursor and was mixed with the reactant gases of oxygen and ammonia. The organosilicon monomer was reservoired in a steel vessel and directly introduced into the deposition chamber without heating. The gas flow rate of the TMS monomer was maintained at $60 \mathrm{sccm}$, while the gas flow ratios $\left(R=\mathrm{NH}_{3} /\left(\mathrm{O}_{2}+\mathrm{NH}_{3}\right)\right)$ were controlled at $0,0.25,0.5,0.75$, and 1 , respectively, with a total gas flow rate $\left(\mathrm{O}_{2}+\mathrm{NH}_{3}\right)$ of $120 \mathrm{sccm}$. The TMS- $\mathrm{O}_{2}-\mathrm{NH}_{3}$ gas mixture was dispersed through a shower head array. The upper anodized electrode was $200-\mathrm{mm}$-diameter and spaced $50 \mathrm{~mm}$ from the lower electrode (grounded) in a nearly symmetrical configuration. The deposition pressure, radio frequency power, and substrate temperature were controlled at $27 \mathrm{~Pa}$ and $70 \mathrm{~W}$, and $120^{\circ} \mathrm{C}$ (controlled by a thermal heater system), respectively.

The optical emission spectra (OES) afforded by the dissociated species in the TMS- $\mathrm{O}_{2}-\mathrm{NH}_{3}$ glow discharge were monitored using optical emission spectroscopy by the Plasus Emicon system (ranged from 200 to $1100 \mathrm{~nm}$ ). The thickness of the deposited films was measured using a surface profile system 
(Dektak 6M, Veeco, New York, NY, USA). The chemical bonding states and compositions of these films were examined using a Fourier transform infrared (FTIR) spectrometry (FT/IR-4100, JASCO, Halifax, NS, Canada) and an X-ray photoelectron (XPS) spectroscope (PHI Quantera SXM ${ }^{\mathrm{TM}}$, ULVAC-PHI, Kanagawa, Japan). Root-mean-square surface roughness $\left(R_{q}\right)$ and surface morphologies of these films were measured and observed by an atomic force microscope (AFM; DI-3100, Vecco, New York, NY, USA) using the tapping-mode and a field emission scanning electron microscope (FE-SEM, JSM-6700F, JEOL, Tokyo, Japan) operated at $15 \mathrm{kV}$. The internal stress, $\sigma_{f}$, resided in the films with a thickness, $d_{f}$, was measured by the beam bending method using a thin film stress measurement instrument (FLX-2320, Tencor, Chicago, IL, USA), and derived from the Stoney formula expressed as [14]:

$$
\sigma_{f}=\frac{E_{s} d_{s}^{2}}{6\left(1-v_{s}\right) d_{f}}\left(\frac{1}{R_{f}}-\frac{1}{R_{0}}\right)
$$

where, $E_{s}, v_{s}$, and $d_{s}$ are Young's modulus, Poisson ratio, and thickness of the substrate, respectively. $R_{0}$ and $R_{f}$ are the radii of the sample curvature before and after the barrier film deposition. The water vapor permeation of the bare and coated PET substrates was measured using a WVTR measurement system (PERMATRAN-W 3/61, MOCON Inc., Minneapolis, MN, USA) at a temperature of $40{ }^{\circ} \mathrm{C}$ with $95 \%$ relative humidity $(\mathrm{RH})$.

\section{Results and Discussion}

The optical emission spectra recorded from the glow discharge of the TMS- $\mathrm{O}_{2}-\mathrm{NH}_{3}$ gas mixture at an ammonia gas flow ratio of 0 (i.e., TMS- $\mathrm{O}_{2}$ gas mixture) and 0.5 are shown in Figure $1 \mathrm{a}, \mathrm{b}$, respectively. As shown in Figure 1a, the TMS monomer reacted with the oxygen gas, resulting in several additional emission lines other than the transition lines determined from the pure oxygen plasma shown in the inset figure. The emission lines at about 558,777 , and $844 \mathrm{~nm}$ were relevant to the transition lines of the oxygen atoms $(\mathrm{O})$ or ions $\left(\mathrm{O}_{2}{ }^{+}\right)[15,16]$. The emission lines at about 450,482 , and $518 \mathrm{~nm}$ were related to the carbon-containing species of $\mathrm{CO}[16,17]$, whereas the emission peak at about $655 \mathrm{~nm}$ was assigned as the atomic emission of excited $\mathrm{H}_{\alpha}[18,19]$. In addition, the emission lines around the short wavelengths with two strong peaks at approximately $288 \mathrm{~nm}$ and $312 \mathrm{~nm}$ emerged from the species of the $\mathrm{SiO}$ and $\mathrm{OH}$ radicals, respectively [18,20-22]. In contrast, when ammonia gas was introduced into the gas mixture, the dominating emission lines over the OES spectrum (Figure 1b) were quite different from those of the glow discharge of the TMS- $\mathrm{O}_{2}$ gas mixture. As referred to in the inset OES spectrum of Figure 1b, measured from the pure ammonia plasma, the peaks at about 314, 335, 356, and $390 \mathrm{~nm}$ were attributed to the transition lines of the nitrogen molecules $\left(\mathrm{N}_{2}\right)$ and the ions of the nitrogen molecules $\left(\mathrm{N}_{2}{ }^{+}\right)[23,24]$. The emission peaks at 426,485 , and $655 \mathrm{~nm}$, in turn, corresponded to the molecular and atomic emissions of excited $\mathrm{H}_{2}, \mathrm{H}_{\beta}, \mathrm{H}_{\alpha}[20,25]$. Furthermore, a significant peak at about $387 \mathrm{~nm}$ emerged from the $\mathrm{CN}^{*} / \mathrm{CH}$ transition [24,26]. Based on the above-mentioned analyses, the oxygen-related plasma lines as well as the emission lines that emerged from the dissociation and oxidation between the oxygen and TMS monomer, such as $\mathrm{SiO}, \mathrm{CO}$, and $\mathrm{OH}$ species, were the main fingerprints determined from the OES spectrum recorded from the TMS- $\mathrm{O}_{2}$ glow discharge. In contrast, the hydrogen- and nitrogen-related emission lines that came from the dissociation of ammonia became the fingerprint of the OES spectrum observed from the glow discharge of the TMS- $\mathrm{O}_{2}-\mathrm{NH}_{3}$ gas mixture. It was also worth noting that the incorporation of the ammonia gas into the $\mathrm{TMS}-\mathrm{O}_{2}$ gas mixture would limit the oxidation of the TMS monomer due to the inlet oxygen gas flow rate decreasing correspondingly, and the relative intensity of the oxidation-related emission lines thus decreased sharply. Figure 2 shows the deposition rate of the film as a function of the ammonia gas flow ratio in the glow discharge. As shown in Figure 2, the deposition of the $\mathrm{SiO}_{x}$ film under the glow discharge of the TMS- $\mathrm{O}_{2}$ gas mixture corresponded to a high deposition rate of approximately $24.8 \mathrm{~nm} / \mathrm{min}$, while a sharp decrease in the deposition rate $(\sim 14.9 \mathrm{~nm} / \mathrm{min})$ was measured from the film synthesized from the ammonia gas incorporated into the reactive gas mixture at a gas flow ratio of 0.25 . It implied that 
the deposition of the $\mathrm{SiO}_{x}$ film was deeply relevant to the reduction in the oxidation-related radicals due to the decrease in the inlet oxygen gas flow rate rather than the increase in the nitrogen-related radicals. The deposition rate of the films under the TMS- $\mathrm{O}_{2}-\mathrm{NH}_{3}$ glow discharge was gradually decreased as the gas flow ratio of the oxygen gas in the reactive gas mixture decreased and the lowest deposition rate of about $8.9 \mathrm{~nm} / \mathrm{min}$ was obtained from the film synthesized from the TMS- $\mathrm{NH}_{3}$ gas mixture.
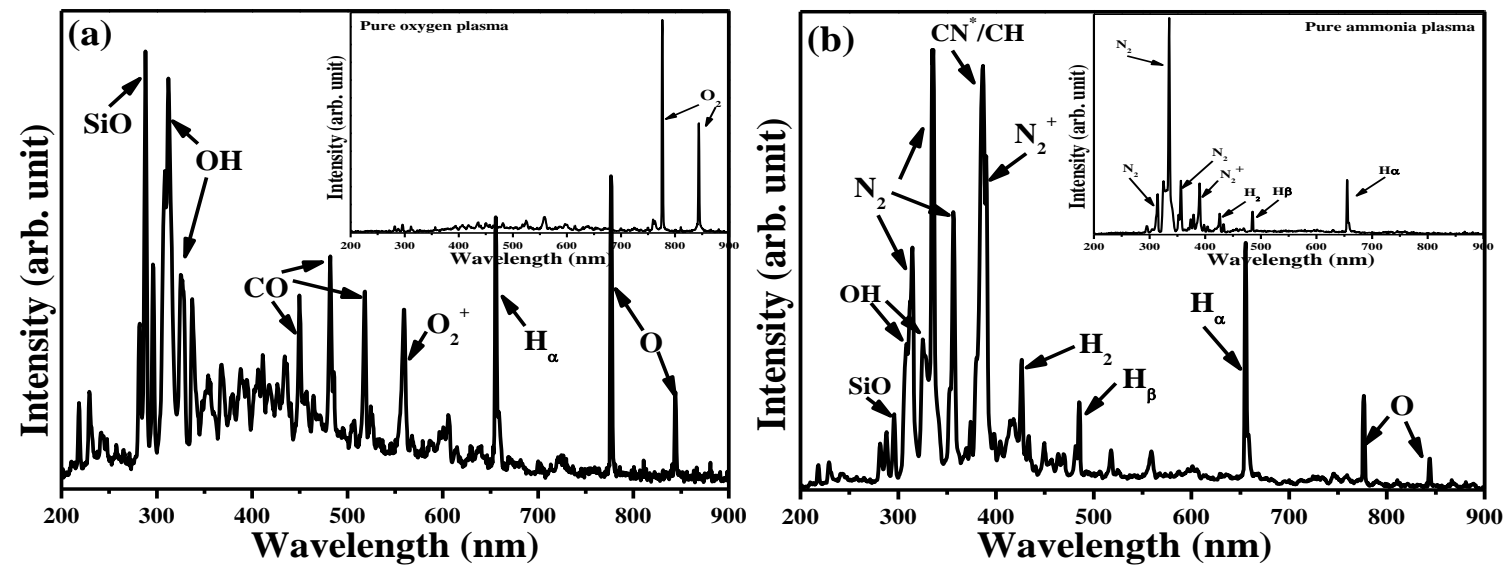

Figure 1. Optical emission spectra (OES) recorded from the glow discharge of the TMS-O $2-\mathrm{NH}_{3}$ gas mixture at an ammonia gas flow ratio of (a) 0 and (b) 0.5 , respectively.

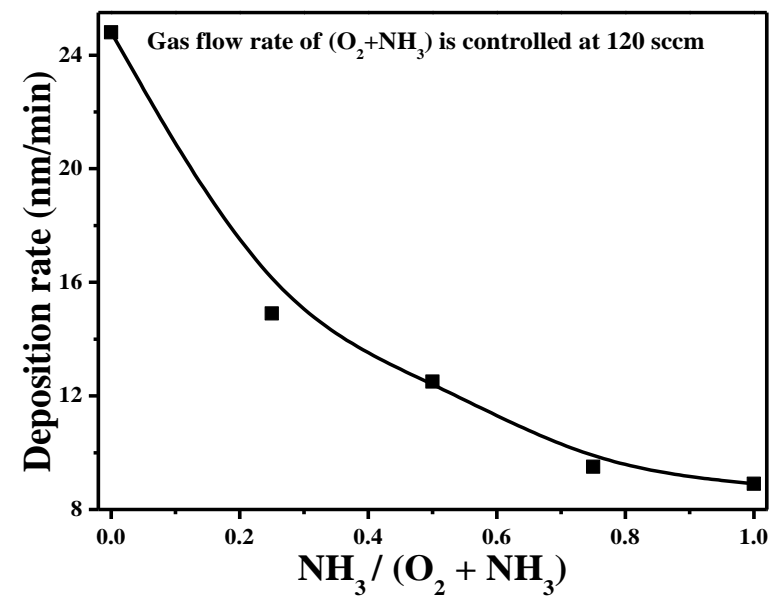

Figure 2. Deposition rates of the films as a function of the ammonia gas flow ratio in the glow discharge.

The FTIR spectra of the films as a function of the ammonia gas flow ratio in the glow discharge are given in Figure 3a. For the film synthesized from the TMS- $\mathrm{O}_{2}$ gas mixture, the stretching and bending modes of the Si-O bonds could be determined at the peaks of 1066 and $817 \mathrm{~cm}^{-1}$, respectively, while the signals related to the hydroxyl $\left(\mathrm{O}-\mathrm{H}\right.$ at around $\left.2800-3700 \mathrm{~cm}^{-1}\right)$ and silanol $(\mathrm{Si}-\mathrm{OH}$ at $940 \mathrm{~cm}^{-1}$ ) were almost absent in the FTIR spectrum [27-29]. When the film was synthesized from the TMS- $\mathrm{O}_{2}-\mathrm{NH}_{3}$ gas mixture at the gas flow ratios of 0.25 and 0.5 , the $\mathrm{Si}-\mathrm{O}$ bond was still the dominant signal over the FTIR spectra without the absorbance signal from the $\mathrm{N}-\mathrm{H}$ bond at around $3200-3600 \mathrm{~cm}^{-1}[27,29]$. However, as the introduced ammonia gas reached a gas flow ratio of 0.75 , the FTIR spectrum of the resulting film exhibited an obvious reduction in the relative intensity of the $\mathrm{Si}-\mathrm{O}$ bond with a satellite peak at about $1101 \mathrm{~cm}^{-1}$. Furthermore, two separated peaks at 1037 and $1103 \mathrm{~cm}^{-1}$, respectively, were observed from the FTIR spectrum of the film prepared using the TMS- $\mathrm{NH}_{3}$ gas mixture. Figure $3 \mathrm{~b}$ highlights the wavenumbers ranging from 700 to $1300 \mathrm{~cm}^{-1}$ shown 
in Figure 3a for further investigating the shifts and evolutions of the main Si-O peak for the films affected by the ammonia gas introduced into the gas mixture. The $\mathrm{Si}-\mathrm{O}$ signal of the films synthesized from the TMS- $\mathrm{O}_{2}-\mathrm{NH}_{3}$ gas mixture at the flow ratios of $0,0.25$, and 0.5 showed almost the same shape with a tail extending to the higher wavenumbers. As quoted from the previous reports, the appearance of this tail was attributed to the signals overlapping from the second asymmetric stretching modes of the longitudinal-optic $\left(\mathrm{LO}_{4}\right)$ and transverse-optic $\left(\mathrm{TO}_{4}\right.$ ) vibration pairs in the $\mathrm{Si}-\mathrm{O}$ cage/ring structures which correlated with the structural disorder and film's porosity in the Si-O-Si networks $[9,30,31]$. The main absorbance peak of the Si-O signal at $1066 \mathrm{~cm}^{-1}$ which appeared in the film synthesized from the TMS- $\mathrm{O}_{2}$ gas mixture gradually shifted to a low wavenumber of $1060 \mathrm{~cm}^{-1}$, as the film was prepared using the ammonia gas at a gas flow ratio of 0.5 . The shift in the peak of the $\mathrm{Si}-\mathrm{O}$ signal was demonstrated as the reduction of the oxygen content $(\mathrm{O} / \mathrm{Si})$ in the deposited films according to the previous reports [32-35]. When the ammonia gas in the gas flow ratio reached 0.75 , the intensity of the Si-O signal was markedly decreased and its peak apparently shifted to $1051 \mathrm{~cm}^{-1}$ with a satellite peak related to the signals overlapped by the $\mathrm{C}-\mathrm{H} / \mathrm{C}-\mathrm{C}$ bonds at about $1101 \mathrm{~cm}^{-1}$ [29]. Such organic $\mathrm{C}-\mathrm{H} / \mathrm{C}-\mathrm{C}$ bonds $\left(\sim 1105 \mathrm{~cm}^{-1}\right)$ and the organosilicon $\left(\mathrm{Si}-\mathrm{CH}_{2}-\mathrm{Si}\right)$ bond absorbed at approximately of $1037 \mathrm{~cm}^{-1}$ became the dominating signals of the FTIR spectrum for the film synthesized from the TMS- $\mathrm{NH}_{3}$ gas mixture $[16,20,29,36]$. In addition, the introduced ammonia gas in the glow discharge also resulted in the films exhibiting two weak signals at about 910 and $736 \mathrm{~cm}^{-1}$ which were assigned to the Si-N and Si-C bonds, respectively $[13,20,29,37]$. Figure 4 a shows the atomic concentration of the films synthesized from various gas flow ratios measured by XPS. All these films were mainly composed of the elemental $\mathrm{Si}$ and $\mathrm{O}$. The elemental $\mathrm{N}$ and $\mathrm{C}$ in the deposited films were both increased as the gas flow ratio of $\mathrm{NH}_{3}$ increased. Moreover, an apparent increase in the carbon content $(\sim 11.2 \%)$ was measured from the film synthesized from the gas mixture without the oxygen incorporated (i.e., the TMS- $\mathrm{NH}_{3}$ gas mixture). The evolutions in the ratios of $\mathrm{O} / \mathrm{Si}$ and $\mathrm{N} / \mathrm{Si}$ as a function of the gas flow ratio are also depicted in Figure $4 \mathrm{~b}$ (the dash line indicates the stoichiometric composition of $\mathrm{SiO}_{2}$ with the ratio of $\mathrm{O} / \mathrm{Si}=2$ ). The film deposited using the $\mathrm{TMS}^{-\mathrm{O}_{2}}$ gas had an $\mathrm{O} / \mathrm{Si}$ ratio of about 2.08, implying an oxygen-rich $\mathrm{SiO}_{2}$ film. When the ammonia gas was introduced into the glow discharge at $R=0.25$, the ratio of the $\mathrm{O} / \mathrm{Si}$ decreased to 2.01 and a low $\mathrm{N}$ content $(\sim 0.8 \%)$ was detected in the film. For the film synthesized from the gas mixture at a ratio of 0.5 , the ratio of the $\mathrm{O} / \mathrm{Si}$ was a little lower than $2(\sim 1.98)$ with the increase in the $\mathrm{N}$ content $(\sim 1.38 \%)$. The O/Si ratio was further decreased to 1.93 as the film was deposited using the TMS- $\mathrm{O}_{2}-\mathrm{NH}_{3}$ gas mixture at a flow ratio of 0.75 . In agreement with the previous reports, the decrease in the $\mathrm{O} / \mathrm{Si}$ ratio also led to the shift in the stretching mode of the Si-O bond from 1066 to $1051 \mathrm{~cm}^{-1}$, as shown in Figure 3b $[19,21,38]$. A sharp reduction in the O/Si ratio ( 1.38) and a high $\mathrm{N} / \mathrm{Si}$ ratio of about 0.16 with a large amount of carbon atoms $(\sim 11.2 \%)$ were measured from the film using the TMS- $\mathrm{NH}_{3}$ gas mixture. This oxygen-deficient film, which implied the incomplete decomposition of the TMS monomer under the glow discharge of the TMS- $\mathrm{NH}_{3}$ gas mixture, was characterized as $\mathrm{Si}-\mathrm{CH}_{2}-\mathrm{Si}$ and $\mathrm{C}-\mathrm{H} / \mathrm{C}-\mathrm{C}$ bonds, as shown in Figure 3b. Accordingly, although the ammonia gas incorporation into the glow discharge functioned to suppress the oxidation of the TMS monomer, only limited nitrogen atoms were introduced into the deposited film and thus a very weak $\mathrm{Si}-\mathrm{N}$ absorbance peak was observed in Figure $3 \mathrm{~b}$. 

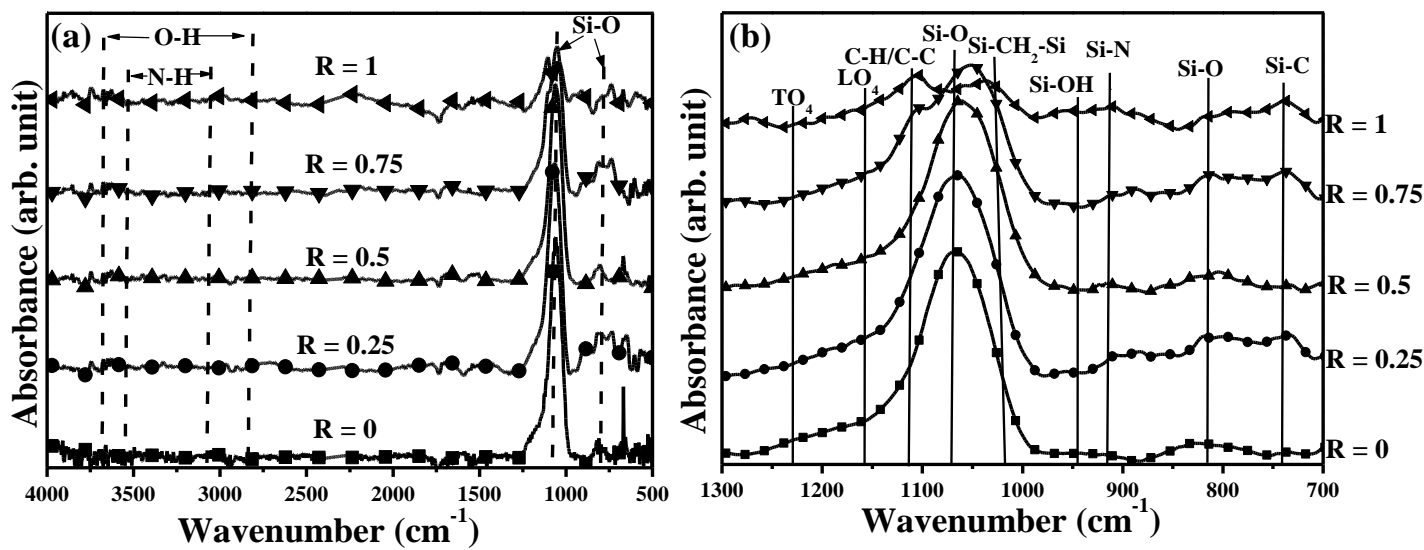

Figure 3. (a) Fourier transform infrared (FTIR) spectra of the films as a function of the ammonia gas flow ratio in the glow discharge and (b) a highlight of the spectra at wavenumbers ranging from 700 to $1300 \mathrm{~cm}^{-1}$.
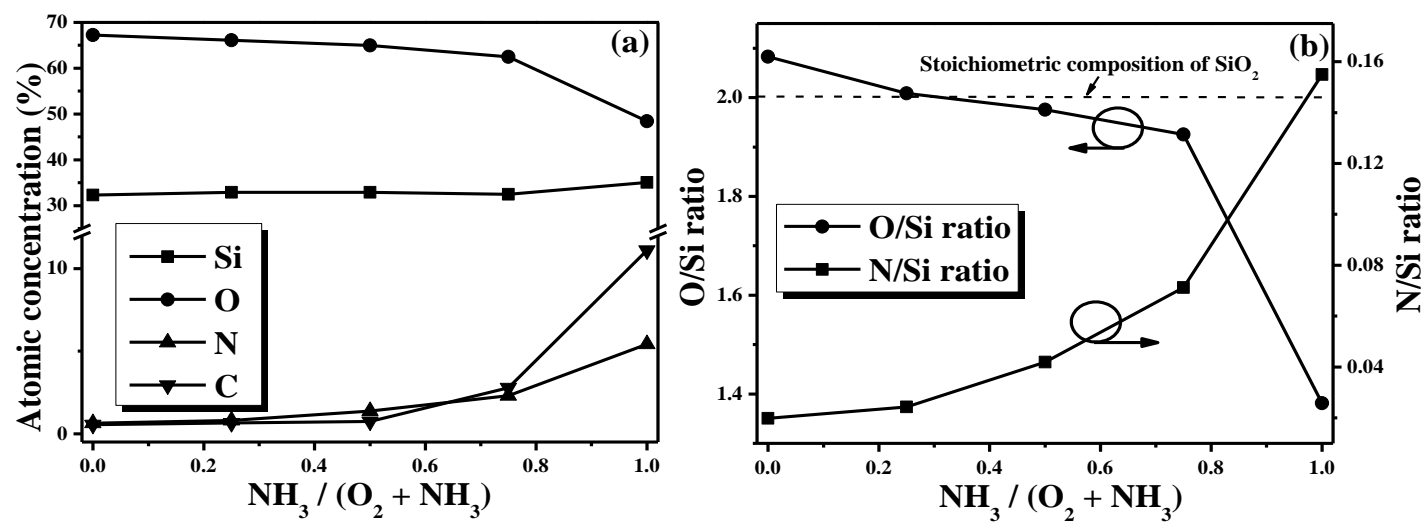

Figure 4. (a) Atomic concentrations and (b) the ratios of $\mathrm{O} / \mathrm{Si}$ and $\mathrm{N} / \mathrm{Si}$ for the films synthesized from various gas flow ratios measured by $\mathrm{X}$-ray photoelectron (XPS).

The surface roughness of these films synthesized from various gas flow ratios are illustrated in Figure 5a-e. Many sharp protrusions with a peak height of about $16.6 \pm 3.42 \mathrm{~nm}$ could be seen from the surface of the film synthesized using the TMS- $\mathrm{O}_{2}$ gas mixture (i.e., $R=0$ ), as shown in Figure 5 a. An apparent reduction in the amount of the protrusions was observed from the film synthesized using the TMS $-\mathrm{O}_{2}-\mathrm{NH}_{3}$ gas mixture at a gas flow ratio of 0.25 (Figure $5 \mathrm{~b}$ ). The decrease in the density of these protrusion structures also led to a low surface roughness of $1.12 \mathrm{~nm}$. As the ammonia gas was introduced to a gas flow ratio of 0.5 , the surface of the synthesized film was almost free from protrusions and the lowest surface roughness of about $0.48 \mathrm{~nm}$ was achieved. However, when the gas flow ratio increased to 0.75 , a few dot-like protrusions appeared on the surface of the deposited film, and therefore the surface roughness was degraded to $0.81 \mathrm{~nm}$. For the film synthesized without oxygen incorporation (i.e., using the TMS- $\mathrm{NH}_{3}$ gas mixture), a surface roughness of about $1.34 \mathrm{~nm}$ was measured as a consequence of large amounts of small dot-like protrusions spread over the film surface with a peak height of about $(12.5 \pm 2.26) \mathrm{nm}$, as shown in Figure 5d. Figure 6a-c further investigated the surface morphologies of the film synthesized from the TMS- $\mathrm{O}_{2}-\mathrm{NH}_{3}$ gas mixture at the gas flow ratios of $0,0.5$, and 1 , respectively. The film synthesized from the TMS- $\mathrm{O}_{2}$ gas mixture which contained sharp protrusions in the AFM image also had many circular patterns with a diameter larger than $200 \mathrm{~nm}$ in the SEM photograph, as presented in Figure 6a, whereas the dot-like protrusions distributed over the film deposited using the TMS- $\mathrm{NH}_{3}$ gas mixture exhibited smaller circles with a diameter of approximately $100 \mathrm{~nm}$ (Figure 6c). Moreover, no significant patterns were observed 
from the film synthesized using the TMS- $\mathrm{O}_{2}-\mathrm{NH}_{3}$ gas mixture at a gas flow ratio of 0.5 (Figure $6 \mathrm{~b}$ ) which also resulted in the lowest surface roughness. As quoted from the previous reports [39-41], the coverage of the voids resulted from the terminated bonds in the Si-O-Si networks and/or the excess oxygen contents to cause the compressive stress residing in the deposited film which was most likely responsible for the appearance of these protrusions. In addition, the additive terminated bonds associated with the $\mathrm{Si}\left(\mathrm{CH}_{3}\right)_{x}$ species and/or the introduced nitrogen contents in the film deposited using the TMS- $\mathrm{NH}_{3}$ gas mixture were ascribed to result in the dot-sized protrusions. The inset figures in Figure 6a,b give the tape-peeling test results of the films deposited onto the PET substrates. A significant peel-off area was observed from the $\mathrm{SiO}_{x}$ film deposited onto the PET, whereas the film synthesized from the TMS- $\mathrm{O}_{2}-\mathrm{NH}_{3}$ gas mixture at a gas flow ratio of 0.5 completely adhered to the PET substrate after the tape-peeling test. According to the ASTM D3359 standard tape-peeling test, the adhesion levels of these two films were ranked at about $3 \mathrm{~B}$ and $5 \mathrm{~B}$, respectively. The relationship between the surface roughness and internal stress residing in the deposited film as a function of the gas flow ratio is presented in Figure 7. All these films synthesized from the TMS- $\mathrm{O}_{2}-\mathrm{NH}_{3}$ gas mixture accumulated compressive stress after deposition onto the silicon substrates as the protrusions attributed to the film coverage on the voids/gas atoms appeared on the surface. Combined with their AFM and SEM measurements, the evolutions on the residual internal stress of the films were closely linked to the surface roughness and morphologies. The fewer the protrusions that appeared on the film surface, the lower the compressive stress and the smoother the surface obtained. A large compressive stress of about $455 \mathrm{MPa}$ resided in the film synthesized without the ammonia gas which led to large protrusions and a rough surface. Moreover, since the inlet ammonia gas facilitated the reduction of the oxygen content for stress relaxation and introduced limited $\mathrm{Si}-\mathrm{C}$ bonds for inducing tensile stress in the deposited film, the compressive stress that resided in the film was effectively released as the ammonia gas flow ratio increased and also resulted in a flattened surface with a decrease in the protrusions. The lowest internal compressive stress of about $123 \mathrm{MPa}$ was obtained from the film deposited using the gas flow ratio of 0.5 while the surface showed almost no protrusions. However, as the introduced ammonia gas reached a gas flow ratio of 0.75 , the dot-like protrusions originating from the incorporation of nitrogen atoms led to the increase in the residual compressive stress of the deposited film. The highest compressive stress of about $651 \mathrm{MPa}$ was then measured from the film synthesized using the TMS- $\mathrm{NH}_{3}$ gas mixture which contained a mass of dot-like protrusions on the film surface. Table 1 summarizes the WVTR of these films as a function of the gas flow ratio in the TMS- $\mathrm{O}_{2}-\mathrm{NH}_{3}$ glow discharge deposited onto the PET substrates (the corresponding surface morphology and residual internal stress when these films were deposited onto the silicon substrate also are listed for comparison). A TMS- $\mathrm{O}_{2}$-synthesized $\mathrm{SiO}_{x}$ film with a thickness of $100 \mathrm{~nm}$ deposited onto the PET substrate could slightly strengthen the barrier property of the bare PET substrate to water vapor permeation from 3.67 to $1.65 \mathrm{~g} / \mathrm{m}^{2} /$ day. In contrast, a one-order-of-magnitude reduction in the WVTR $\left(\sim 0.19 \mathrm{~g} / \mathrm{m}^{2} /\right.$ day $)$ was obtained from the PET substrate which was coated with the film using the TMS- $\mathrm{O}_{2}-\mathrm{NH}_{3}$ gas mixture at a flow ratio of 0.25 . The marked enhancement on the barrier property was closely linked to the release of the stress residing in the deposited film as a consequence of the introduced nitrogen atoms in the deposited film under the TMS- $\mathrm{O}_{2}-\mathrm{NH}_{3}$ gas mixture which functioned to fill the voids in the deposited film, and thereby to improve the quality and density of the $\mathrm{SiO}_{x}$ film. Accordingly, the film that had the lowest internal compressive stress synthesized using a gas flow ratio of 0.5 coated onto the PET substrate could significantly optimize the resulting WVTR value to about $0.06 \mathrm{~g} / \mathrm{m}^{2} /$ day. However, a significant degradation in the WVTR $\left(\sim 0.57 \mathrm{~g} / \mathrm{m}^{2} /\right.$ day $)$ was measured from the PET substrate coated with the film synthesized from the gas flow ratio of 0.75 which also corresponded to the increase in the residual compressive stress ( 250 MPa). The film deposited under the TMS- $\mathrm{NH}_{3}$ glow discharge, which had a large compressive stress, was almost ineffective in enhancing the barrier property of the PET substrate as evidence of the high WVTR $\left(\sim 3.43 \mathrm{~g} / \mathrm{m}^{2} /\right.$ day $)$. 

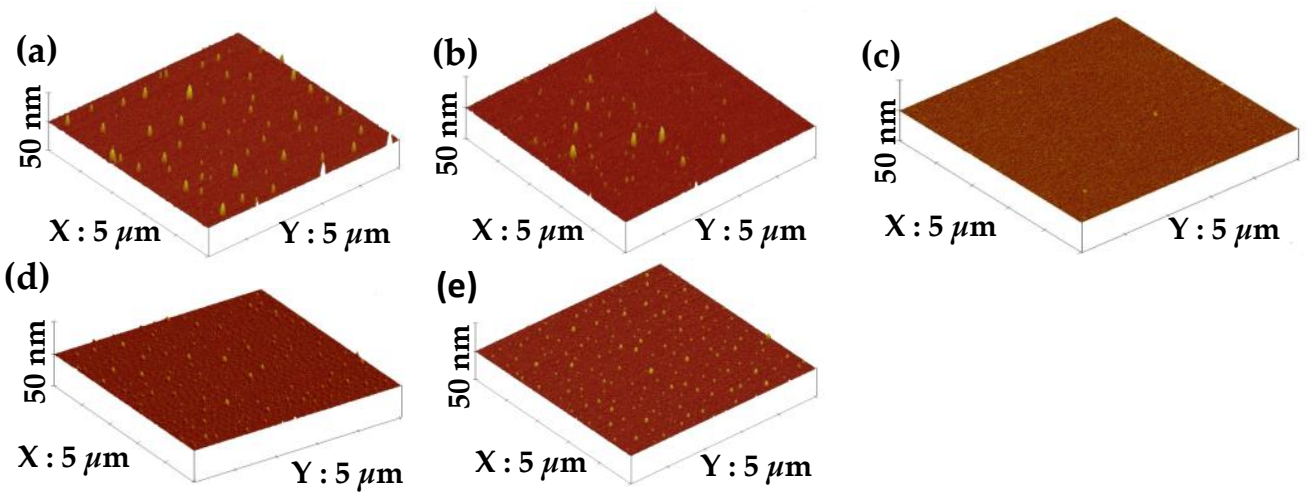

Figure 5. Surface roughness of the films synthesized from the gas flow ratios of (a) 0 ; (b) 0.25 ; (c) 0.5 ; (d) 0.75 ; and (e) 1 , respectively.
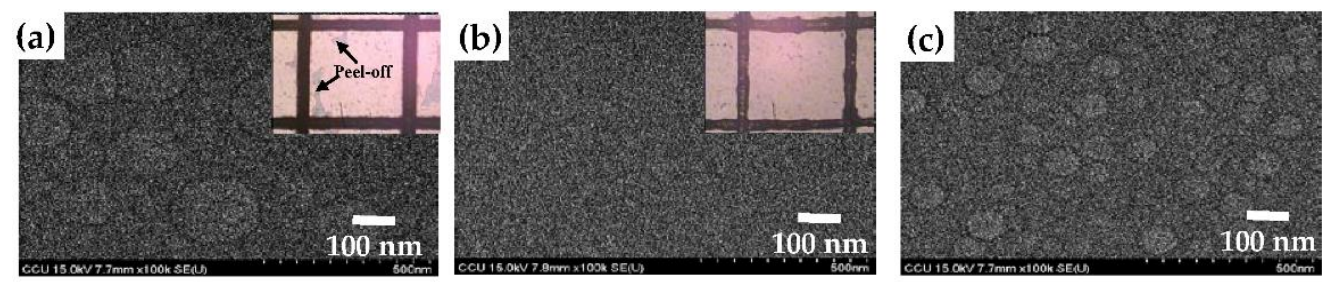

Figure 6. Surface morphologies of the films synthesized from the gas flow ratios of (a) 0 ; (b) 0.5 ; and (c) 1 , respectively (the inset figures show the tape-peeling test result).

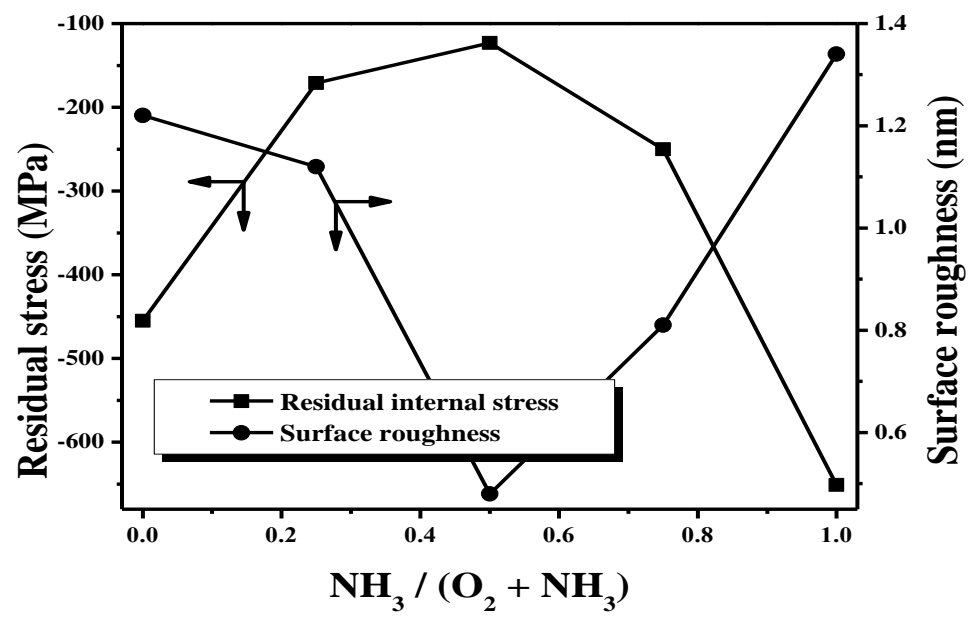

Figure 7. The relationship between the surface roughness and internal stress residing in the deposited film as a function of the gas flow ratio.

Table 1. Water vapor transmission rates (WVTRs) of the films as a function of the gas flow ratio in the TMS- $\mathrm{O}_{2}-\mathrm{NH}_{3}$ glow discharge deposited on the PET substrate, as well as their residual internal stresses and surface roughness when deposited onto the silicon substrate ${ }^{1}$.

\begin{tabular}{cccc}
\hline Gas Flow Ratio $\mathbf{N H}_{\mathbf{3}} /\left(\mathbf{N H}_{\mathbf{3}}+\mathbf{O}_{\mathbf{2}}\right)$ & WVTR $\mathbf{( g / \mathbf { m } ^ { 2 } / \text { day) }}$ & Residual Stress $\mathbf{( M P a})$ & Surface Roughness $(\mathbf{n m})$ \\
\hline 0 & 1.65 & -455 & 1.22 \\
0.25 & 0.19 & -171 & 1.12 \\
0.5 & 0.06 & -123 & 0.48 \\
0.75 & 0.57 & -250 & 0.81 \\
1 & 3.43 & -651 & 1.34 \\
\hline
\end{tabular}

${ }^{1}$ Measurements taken at $40{ }^{\circ} \mathrm{C}$ with $95 \% \mathrm{RH}$. 


\section{Conclusions}

In conclusion, the impact on the glow discharge of the ammonia gas introduced into the TMS- $\mathrm{O}_{2}$ gas mixture was studied using the in situ OES observation. The glow discharge using only the TMS and oxygen gas mixture was characterized by the transition lines of oxygen atoms/molecules $(\mathrm{O}$ and $\mathrm{O}^{2+}$ lines) with the species of $\mathrm{SiO}$ and $\mathrm{OH}$ radicals, whereas the emissions associated with the nitrogenand hydrogen-related lines and $\mathrm{CN}^{*} / \mathrm{CH}$ lines ere predominated over the OES spectra obtained from the glow discharge incorporated with the ammonia gas. This revealed that the incorporation of the ammonia gas in the glow discharge facilitated suppressing energetic oxygen-related radicals, thereby slowing down the deposition rates of the synthesized films. Based on the measurements of the chemical bond configurations and elemental compositions, the films synthesized from the TMS- $\mathrm{O}_{2}-\mathrm{NH}_{3}$ gas mixture were basically constructed from Si-O-Si networks with a slight decrease in the oxygen content and the limited incorporation of nitrogen and carbon atoms. The small amounts of the nitrogen and carbon atoms incorporated into the deposited film resulted in a flat surface with a decrease in the protrusions originating from the structural voids. The lowest surface roughness $(\sim 0.48 \mathrm{~nm})$ with the near-absence of protrusions was obtained from the film synthesized from the TMS- $\mathrm{O}_{2}-\mathrm{NH}_{3}$ gas mixture at a gas flow ratio of 0.5 . However, as the introduced ammonia gas in the glow discharge increased to a gas flow ratio of $0.75, \mathrm{C}-\mathrm{H} / \mathrm{C}-\mathrm{C}$ and species of $\mathrm{Si}\left(\mathrm{CH}_{3}\right)_{x}$ bonds apparently appeared in the deposited film as a consequence of the apparent increase in the carbon content. A significant reduction in the atomic ratio of $\mathrm{O} / \mathrm{Si}$, which showed dominating $\mathrm{C}-\mathrm{H} / \mathrm{C}-\mathrm{C}$ and $\mathrm{Si}-\mathrm{CH}_{2}-\mathrm{Si}$ bonds in the FTIR spectrum, was then obtained from the film synthesized from the TMS- $\mathrm{NH}_{3}$ gas mixture. The surface roughness of the film that contained considerable $\mathrm{C}-\mathrm{H}$ and $\mathrm{Si}-\mathrm{CH}$ bonds was apparently increased to $1.34 \mathrm{~nm}$. The formation of the protrusion structures was found to be deeply correlated with the degree of the internal stress residing in the deposited film. The lower the residual compressive stress, the fewer the protrusions and the lower the surface roughness measured. Accordingly, the WVTR of the PET substrate coated with the film synthesized from the TMS- $\mathrm{O}_{2}$ gas mixture ( $\sim 1.65 \mathrm{~g} / \mathrm{m}^{2} /$ day) apparently decreased to $0.06 \mathrm{~g} / \mathrm{m}^{2} /$ day as the substrate was coated with the film synthesized from the glow discharge incorporated with ammonia gas at a gas flow ratio of 0.5 . The enhancement of the deposited film as a barrier to water vapor permeation was attributed to the improvement in the $\mathrm{Si}-\mathrm{O}-\mathrm{Si}$ networks originating from the prevention of void formation due to the limited incorporation of nitrogen atoms, and thereby it possessed the lowest residual compressive stress and exhibited the smoothest surface roughness.

Acknowledgments: This work was supported by the Ministry of Science and Technology under Ministry of Science and Technology (MOST) 105-2622-E-150-004-CC2 and Industrial Technology Research Institute (ITRI)ITRI under A200-105BA2.

Author Contributions: Day-Shan Liu organized and designed the experiment procedures; Tai-Hong and Chun-Hao Chang supported the measurement results and wrote this paper; Hua-Wen Liu, Shao-Kai Lu, and Yi-Cyuan Lin executed the film depositions and resulting materials analysis. All authors read and approved the final version of the manuscript to be submitted.

Conflicts of Interest: The authors declare no conflict of interest.

\section{References}

1. Schwanitz, K.; Klein, S.; Stolley, T.; Rohde, M.; Severin, D.; Trassl, R. Anti-reflective microcrystalline silicon oxide p-layer for thin-film silicon solar cells on ZnO. Sol. Energy Mater. Sol. Cells 2012, 105, $187-191$. [CrossRef]

2. Cui, J.; Grant, N.; Lennon, A. Effective surface passivation of p-type crystalline silicon with silicon oxides formed by light-induced anodisation. Appl. Surf. Sci. 2014, 323, 40-44. [CrossRef]

3. Cataldo, G.; Wollack, E.J.; Brown, A.D.; Miller, K.H. Infrared dielectric properties of low-stress silicon oxide. Opt. Lett. 2016, 41, 1364-1367. [CrossRef] [PubMed] 
4. Jang, G.; Lee, S.J.; Kim, Y.C.; Lee, S.H.; Biswas, P.; Lee, W.; Myoung, J.M. Device characteristics of amorphous indium-gallium-zinc-oxide channel capped with silicon oxide passivation layers. Mater. Sci. Semicond. Process. 2016, 49, 34-39. [CrossRef]

5. Wu, C.Y.; Chen, W.C.; Liu, D.S. Surface modification layer deposition on flexible substrates by plasma-enhanced chemical vapour deposition using tetramethylsilane-oxygen gas mixture. J. Phys. D Appl. Phys. 2008, 41, 225305. [CrossRef]

6. Schneider, J.; Akbar, M.I.; Dutroncy, J.; Kiesler, D.; Leins, M.; Schulz, A.; Walker, M.; Schumacher, U.; Stroth, U. Silicon Oxide Barrier Coatings Deposited on Polymer Materials for Applications in Food Packaging Industry. Plasma Process. Polym. 2009, 6, S700-S704. [CrossRef]

7. Jeong, C.H.; Lee, J.H.; Lim, J.T.; Cho, N.G.; Moon, C.H.; Yeom, G.Y. Deposition of $\mathrm{SiO}_{2}$ by Plasma Enhanced Chemical Vapor Deposition as the Diffusion Barrier to Polymer Substrates. Jpn. J. Appl. Phys. 2005, 44, 1022. [CrossRef]

8. Wuu, D.S.; Chen, T.N.; Wu, C.C.; Chiang, C.C.; Chen, Y.P.; Horng, R.H.; Juang, F.S. Transparent Barrier Coatings for Flexible Organic Light-Emitting Diode Applications. Chem. Vapor Depos. 2006, 12, $220-224$. [CrossRef]

9. Wu, C.Y.; Liao, R.M.; Lai, L.W.; Jeng, M.S.; Liu, D.S. Organosilicon/silicon oxide gas barrier structure encapsulated flexible plastic substrate by using plasma-enhanced chemical vapor deposition. Surf. Coat. Technol. 2012, 206, 4685-4691. [CrossRef]

10. Alipour, N.; Gedde, U.W.; Hedenqvist, M.S.; Yu, S.; Roth, S.; Brüning, K.; Vieyres, A.; Schneider, K. Structure and Properties of polyethylene-based and EVOH-based multilayered films with layer thickness of $150 \mathrm{~nm}$ and greater. Eur. Polym. J. 2015, 64, 36-51. [CrossRef]

11. Lau, K.; Weber, J.; Bartzsch, H.; Frach, P. Reactive pulse magnetron sputtered $\mathrm{SiO}_{x} \mathrm{~N}_{y}$ coatings on polymers. Thin Solid Films 2009, 517, 3110-3114. [CrossRef]

12. Lee, D.K.; Shin, H.J.; Sohn, S.H. Characteristics of Silicon Oxynitride Barrier Films Grown on Poly(ethylene naphthalate) by Ion-Beam-Assisted Deposition. Jpn. J. Appl. Phys. 2010, 49, 05EA14. [CrossRef]

13. Jin, S.B.; Lee, J.S.; Choi, Y.S.; Cho, I.S.; Han, J.G. Gas barrier properties of SiON films deposited by plasma enhanced chemical vapor deposition at low temperature as a function of the plasma process parameters. Surf. Coat. Technol. 2013, 228, S490-S494. [CrossRef]

14. Bhatt, V.; Chandra, S.; Kumar, S.; Rauthan, C.M.S.; Dixit, P.N. Stress evaluation of RF sputtered silicon dioxide films for MEMS. Indian J. Pure Appl. Phys. 2007, 45, 377.

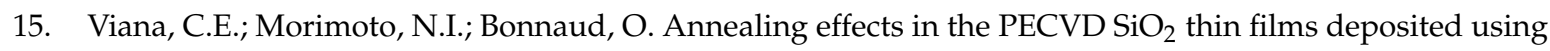
TEOS, Ar and $\mathrm{O}_{2}$ mixture. Microelectron. Reliab. 2000, 40, 613-616. [CrossRef]

16. Abbasi-Firouzjah, M.; Hosseini, S.; Shariat, M.; Shokri, B. The effect of TEOS plasma parameters on the silicon dioxide. J. Non-Cryst. Solids 2013, 368, 86-92. [CrossRef]

17. Lasorsa, C.; Morando, P.J.; Rodrigo, A. Effects of the plasma oxygen concentration on the formation of $\mathrm{SiO}_{x} \mathrm{C}_{y}$ films by low temperature PECVD. Surf. Coat. Technol. 2005, 194, 42-47. [CrossRef]

18. Lien, S.Y.; Chang, Y.Y.; Cho, Y.S.; Wang, J.H.; Weng, K.W.; Chao, C.H.; Chen, C.F. Characterization of HF-PECVD a-Si:H thin film solar cells by using OES studies. J. Non-Cryst. Solids 2011, 357, 161. [CrossRef]

19. Lin, T.Y.; Lee, C.T. Organosilicon function of gas barrier films purely deposited by inductively coupled plasma chemical vapor deposition system. J. Alloy. Compd. 2012, 542, 11-16. [CrossRef]

20. Thomas, L.; Maillé, L.; Badie, J.M.; Ducarroir, M. Microwave plasma chemical vapour deposition of tetramethylsilane: Correlations between optical emission spectroscopy and film characteristics. Surf. Coat. Technol. 2001, 142-144, 314-320. [CrossRef]

21. Chaiwong, C.; Rachtanapun, P.; Sarapirom, S.; Boonyawan, D. Plasma polymerization of hexamethyldisiloxane: Investigation of the effect of carrier gas related to the film properties. Surf. Coat. Technol. 2013, 229, 12-17. [CrossRef]

22. Burkert, A.; Müller, D.; Paa, W. Si and SiO detection in a HMDSO/propane/air flame using spatially resolved optical emission spectroscopy (OES). J. Quant. Spectrosc. Radiat. Transf. 2013, 114, 101-108. [CrossRef]

23. Grotjahn, T.; Aslanbas, Ö.; Mee, M.; König, M.; Meier, S. Plasma parameter investigation during plasma-enhanced chemical vapor deposition of silicon-containing diamond-like carbon films. Surf. Coat. Technol. 2013, 237, 126-134. [CrossRef]

24. Fujiyama-Novak, J.H.; Gaddam, C.K.; Das, D.; Vander Wal, R.L.; Ward, B. Detection of explosives by plasma optical emission spectroscopy. Sens. Actuators B 2013, 176, 985-993. [CrossRef] 
25. Meškinis, Š.; Andrulevičius, M.; Šlapikas, K.; Iljinas, A.; Gudaitis, R.; Puišo, J.; Tamulevičius, S. Growth and properties of the ion beam deposited $\mathrm{SiO}_{x}$ containing DLC films. Vacuum 2009, 83, S121-S123. [CrossRef]

26. Bogdanowicz, R.; Golunski, L.; Sobaszek, M. Spatial characterization of $\mathrm{H}_{2}: \mathrm{CH}_{4}$ dissociation level in microwave ECR plasma source by fibre-optic OES. Eur. Phys. J. Spec. Top. 2013, 222, 2223-2232. [CrossRef]

27. Vogt, M.; Hauptmann, R. Plasma-deposited passivation layers for moisture and water protection. Surf. Coat. Technol. 1995, 74-75, 676-681. [CrossRef]

28. Liu, D.S.; Wu, C.Y. Adhesion enhancement of hard coatings deposited on flexible plastic substrates using an interfacial buffer layer. J. Phys. D Appl. Phys. 2010, 43, 175301. [CrossRef]

29. Lee, J.H.; Jeong, C.H.; Lim, J.T.; Zavaleyev, V.A.; Kyung, S.J.; Yeom, G.Y. $\mathrm{SiO}_{x} \mathrm{~N}_{y}$ thin film deposited by plasma enhanced chemical vapor deposition at low temperature using $\mathrm{HMDS}-\mathrm{O}_{2}-\mathrm{NH}_{3}-\mathrm{Ar}$ gas mixtures. Surf. Coat. Technol. 2007, 201, 4957-4960. [CrossRef]

30. Kirk, C.T. Quantitative analysis of the effect of disorder-induced mode coupling on infrared absorption in silica. Phys. Rev. B Condens. Matter 1998, 38, 1255. [CrossRef]

31. Katumba, G.; Mwakikunga, B.W.; Mothibinyabe, T.R. FTIR and Raman Spectroscopy of Carbon Nanoparticles in $\mathrm{SiO}_{2}, \mathrm{ZnO}$ and $\mathrm{NiO}$ Matrices. Nanoscale Res. Lett. 2008, 3, 421. [CrossRef]

32. Pai, P.G.; Chao, S.S.; Takagi, Y.; Lucovsky, G. Infrared spectroscopic study of $\mathrm{SiO}_{x}$ films produced by plasma enhanced chemical vapor deposition. J. Vac. Sci. Technol. A 1986, 4, 689-694. [CrossRef]

33. Schäfer, J.; Foest, R.; Quade, A.; Ohl, A.; Weltmann, K.D. Local deposition of $\mathrm{SiO}_{x}$ plasma polymer films by a miniaturized atmospheric pressure plasma jet (APPJ). J. Phys. D Appl. Phys. 2008, 41, 194010. [CrossRef]

34. Satriano, C.; Marletta, G.; Kasemo, B. Oxygen plasma-induced conversion of polysiloxane into hydrophilic and smooth $\mathrm{SiO}_{x}$ surfaces. Surf. Interface Anal. 2008, 40, 649-656. [CrossRef]

35. Oyaidu, T.; Ogawa, Y.; Tsurumaki, K.; Ohdaira, K.; Matsumura, H. Formation of gas barrier films by Cat-CVD method using organic silicon compounds. Thin Solid Films 2008, 516, 604-606. [CrossRef]

36. Lin, Y.S.; Hu, C.H.; Hsiao, C.A. Enhanced scratch resistance of flexible carbon fiber-reinforced polymer composites by low temperature plasma-polymerized organosilicon oxynitride: The effects of nitrogen addition. Compos. Sci. Technol. 2011, 71, 1579-1586. [CrossRef]

37. Shim, J.; Yoon, H.G.; Na, S.H.; Kim, I.; Kwak, S. Silicon oxynitride gas barrier coatings on poly(ether sulfone) by plasma-enhanced chemical vapor deposition. Surf. Coat. Technol. 2008, 202, 2844-2849. [CrossRef]

38. Pham, T.T.T.; Lee, J.H.; Kim, Y.S.; Yeom, G.Y. Properties of $\mathrm{Si}_{x} \mathrm{~N}_{y}$ thin film deposited by plasma enhanced chemical vapor deposition at low temperature using $\mathrm{SiH}_{4} / \mathrm{NH}_{3} / \mathrm{Ar}$ as diffusion barrier film. Surf. Coat. Technol. 2008, 202, 5617-5620. [CrossRef]

39. Babayan, S.E.; Jeong, J.Y.; Schütze, A.; Tu, V.J.; Moravej, M.; Selwyn, G.S.; Hicks, R.F. Deposition of silicon dioxide films with a non-equilibrium atmospheric-pressure plasma jet. Plasma Sources Sci. Technol. 2001, 10, 573. [CrossRef]

40. Xu, C.H.; Qin, X.M.; Guo, W.H.; Li, Y. Protrusion and whisker growth on tin coated copper substrate under stresses. Mater. Sci. Technol. 2011, 27, 1271-1274. [CrossRef]

41. Lu, S.K.; Chen, S.C.; Chen, T.H.; Lai, L.W.; Liao, R.M.; Liu, D.S. Barrier property and mechanical flexibility of stress controlled organosilicon/silicon oxide coatings on plastic substrates. Surf. Coat. Technol. 2015, 280, 92-99. [CrossRef]

(C) 2017 by the authors; licensee MDPI, Basel, Switzerland. This article is an open access article distributed under the terms and conditions of the Creative Commons Attribution (CC-BY) license (http://creativecommons.org/licenses/by/4.0/). 